\title{
SUBACUTE CORTICAL CEREBELLAR DEGENERATION AND ITS RELATION TO CARCINOMA*
}

\author{
BY \\ W. RUSSELL BRAIN, PETER M. DANIEL, and J. GODWIN GREENFIELD \\ From Chase Farm Hospital, Enfield, the Department of Pathology, the Radcliffe Infirmary, \\ and the Nuffield Department of Surgery, University of Oxford, and the \\ Pathological Laboratories of the National Hospital, \\ Queen Square, London
}

Since Casper (1929) published a case of subacute cortical cerebellar degeneration associated with carcinoma, a number of cases with a similar association has been recorded. In the earlier cases (Parker and Kernohan, 1933 ; Greenfield, 1934) little or no comment was made on the association, but as more cases were reported it became evident that carcinoma played some part either in the aetiology or at least in the tempo of the nervous disease. It is however clear that not all cases of subacute cortical cerebellar degeneration are associated with carcinoma. It may therefore be useful to consider how common this association is, and what role carcinoma plays in causing or hastening the cortical cerebellar degeneration.

We have been able to collect from the literature only eight cases of cortical cerebellar degeneration in which the disease ran its course from onset to death in under 12 months, and are able to add four new cases in three of which there was also carcinoma. Even adding five additional non-familial cases in which the duration of the disease was under, or slightly over two years, the group is still a very small one but, although of no value for statistical study, its survey may throw light on the question of the relationship of the cerebellar disease to carcinoma.

It is probable that only a small proportion of the cases which fall in this group are recorded; only so is it possible to explain the silence of the American literature on the subject since the early case report of Parker and Kernohan (1933). No doubt also symptoms of cerebellar disease are apt to be attributed to metastases when they appear in bed-ridden patients dying of carcinoma. The

* Much of the subject matter of this paper formed part of the Hughlings Jackson Lecture given at the Neurological Institute, Montreal, in September, 1950, by J. Godwin Greenfield. paucity of recorded cases, whatever its cause, is unfortunate since our knowledge of the aetiology and pathogenesis of cortical cerebellar degeneration is so slight that any addition to our knowledge, however indirect it may appear to be, is of value.

As it is notoriously difficult to distinguish clinically between the various forms of cerebellar degeneration or even to distinguish them from spinal cases of Friedreich type, we have confined our survey to cases in which a necropsy examination of the cerebellum has been made.

\section{Case Reports}

Case 1.-Mrs. J. B., aged 61, was admitted to Chase Farm Hospital on June 6, 1945, under Dr. Russell Brain, and died there on July 17 of the same year. Her history was that two months before admission she had felt weak and ill, had lost interest in her housework, and had had unpleasant, confused dreams. Soon after this her gait became unsteady, both legs being affected, but she did not fall. Her gait became progressively worse. Two weeks before admission she complained that her vision was blurred and there was occasional diplopia, and soon after this she had difficulty with her speech ; there was some difficulty in finding the right word, and her diction became indistinct. She also suffered from excessive salivation. During all this time she had generalized headaches, and cramp-like pains in the legs which kept her awake at night.

When examined at Chase Farm Hospital she was a spare, middle-aged woman, whose speech showed a combination of dysarthria and aphasia; there was some alexia for long words ; no mental impairment was evident at this time. Her vision was good, and her visual fields full. There was no papilloedema. Nystagmus was present on lateral deviation of the eyes. It was rather slow on looking to the right and slower and less well sustained to the left. On looking upwards there were occasional nystagmoid jerks. No limitation of the external ocular movements was found. The left side of the palate rose rather further than the right 
on phonation and the tongue was protruded to the right of the midline. No other evidence of cranial nerve involvement was found.

There was no evident weakness or modification of tone in the limbs but some ataxia was present, more in the legs than in the arms, and least in the right arm. Dysdiadokokinesis was also more evident in the left arm than the right. The gait was very unsteady; she could not walk along a straight line; but there was no true Rombergism. The deep reflexes were rather exaggerated in the arms, especially the left, the knee jerks were normal and the ankle jerks rather feeble. No abdominal reflexes were obtained. The plantar refiexes were flexor in type. No disturbance of the sensory system was found.

A lumbar puncture was done on June 7 and colourless cerebrospinal fluid was obtained. It contained 48 lymphocytes per c.mm., $100 \mathrm{mg}$. protein per $100 \mathrm{ml}$. with positive globulin reactions. The Lange gold sol gave a strong paretic reaction, 5555421100. The Wassermann reaction was negative in blood and cerebrospinal fluid.

The clinical condition taken in conjunction with the findings in the cerebrospinal fluid made the diagnosis of subacute spino-cerebellar degeneration reasonably certain. During her stay in hospital there was progressive mental deterioration and dysarthria so that her speech became almost unintelligible. She was unable to sit up owing to giddiness. She lapsed into coma on July 13 and died on July 17 about three and a half months after the onset of her illness.

Necropsy Report.-A post-mortem examination was made by Dr. Greenfield 16 hours after death. The only external evidence of disease was a scar in the right iliac fossa. Examination of the organs of the body cavity showed the right lung slightly adherent by purulent lymph to the chest wall over the upper part of the right lower lobe. The upper lobe and the upper part of the lower lobe of the right lung were in a condition of diffuse bronchopneumonia. The left lung was oedematous throughout with atrophic emphysema. In the heart there was slight patency of the foramen ovale, and the wall was rather thin and brown. The stomach and liver were healthy ; the lower coils of the small intestine were matted together by adhesions and there was some kinking of the ascending colon; the rest of the colon was normal, the appendix being present. The uterus contained a small central fibroid, the wall being otherwise thin. In the right evary there were two seft masses of carcinoma, each the size of a cherry ; one was degenerated in its centre. Masses of enlarged glands lay in the right iliac fossa and along the aorta, chiefly in front and at its sides. They were firm and white on section. The whole mass with the abdominal aorta weighed $450 \mathrm{~g}$. A few small firm white glands were present also in the mesentery.

Histologically the tumour in the ovary and glands consisted of a number of small rounded collections of cells resembling collapsed acini, but seldom having a lumen. These small cell groups were separated from one another by very fine collagenous strands, and rather thicker collagenous septa divided the tumour into larger irregularly rounded masses. In most places the tumour cells were cuboidal with a fairly large, slightly granular cell body and irregularly rounded hyperchromic nucleus. In a few places they were more columnar and arranged in palisades along a basement membrane. Many larger multinucleated cells were also present, and in many of these the nucleus was imperfectly divided. Mitoses were fairly numerous. In some of the glands there was central necrosis of the larger groups of cells. In the Fallopian tube the arrangement of cells in small groups was lost, the cell bodies were more irregular in size and generally smaller, but a few acinar arrangements were seen here also. The thyroid gland presented a remarkable degree of lymphocytic infiltration with considerable swelling of the acinar epithelial cells, but less destruction of parenchymal tissue and less fibrosis than is usual in Riedel's struma. Many acini were normal, but many were small with irregularly swollen epithelium and very little colloid, and all gradations between these were seen.

The brain and spinal cord were removed and fixed entire in $15 \%$ formol-saline solution. The only naked eye abnormality was that the cerebellar folia were rather better demarcated than normal. The brain and cerebellum were both shrunken, the brain entire weighing $1,150 \mathrm{~g}$. and the pons, cerebellum, and medulla $150 \mathrm{~g}$. Frozen sections in the transverse plane were made at various levels of the spinal cord, medulla, pons and midbrain, and similar sections of the cerebellum in the sagittal and parasagittal planes and of the basal ganglia in the coronal plane. These were stained by haematein and Scharlach $\mathbf{R}$ for early myelin degeneration. Those from the cerebellum, medulla, and spinal cord were also stained by the Da Fano-Bielschowsky technique. Thin slices from neighbouring areas of the cord and brain stem, but not of the cerebellum, were treated by the Marchi-Busch (iodate-osmic acid) technique. Sections were also made after celloidin embedding from similar areas and from several areas of the cerebral cortex.

In the lumbar cord there was early Marchi degeneration in the pyramidal tracts which also showed itself in Scharlach $\mathbf{R}$ sections as irregular granular masses of lipid replacing some of the myelin rings. These took a rather redder stain than the surrounding myelin sheaths and were less anisotropic, but were not brightly sudanophilic. There was, both at this and higher levels of the spinal cord, some excess of lipochrome in the larger nerve cells.

At the thoracic level degeneration in a more advanced stage was seen in the direct spino-cerebellar tracts. Here the lipid was brightly sudanophilic and most of it was collected in large fat-granule cells. A zone of sudanophilic lipid was also seen round some of the small vessels.

In the cervical enlargement this degeneration involved a larger area on the lateral surface of the cord and on one side extended as far anteriorly as the posterior margin of the ventral horn. It was not however evident in sections stained by the Weigert-Pal technique.

In sections at the lower levels of the medulla, below the fourth ventricle the degeneration in the dorsal spino-cerebellar tract was very evident with Scharlach 


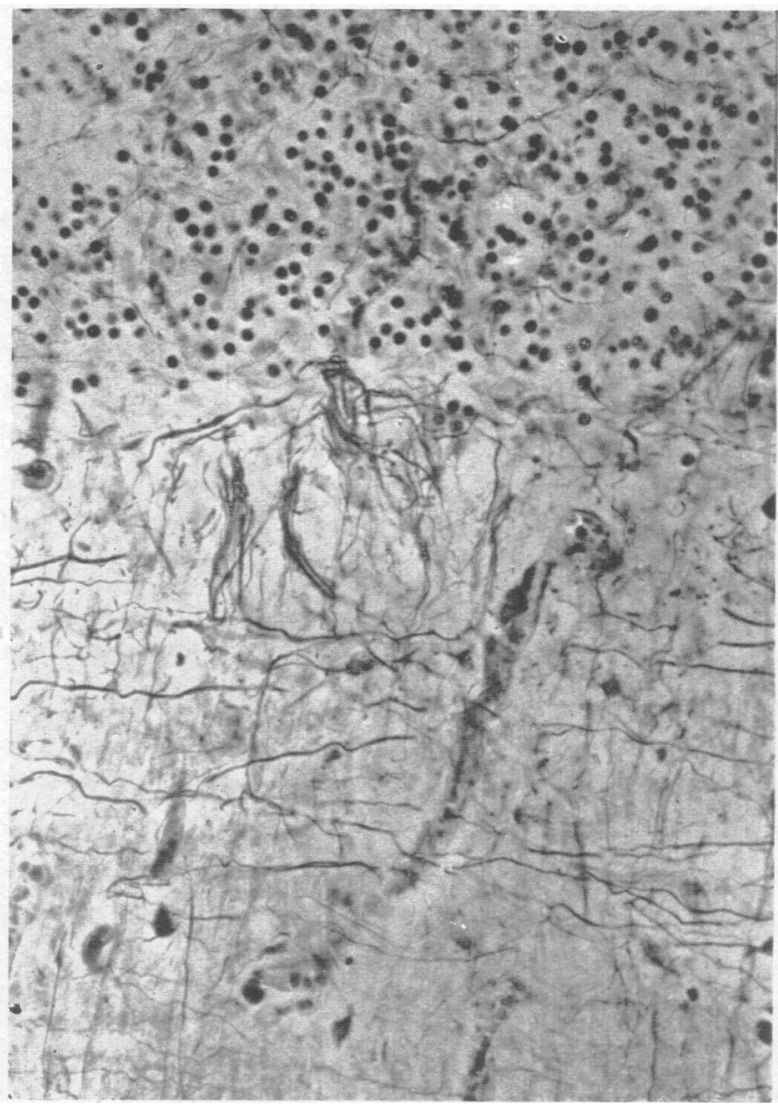

FIG. 1

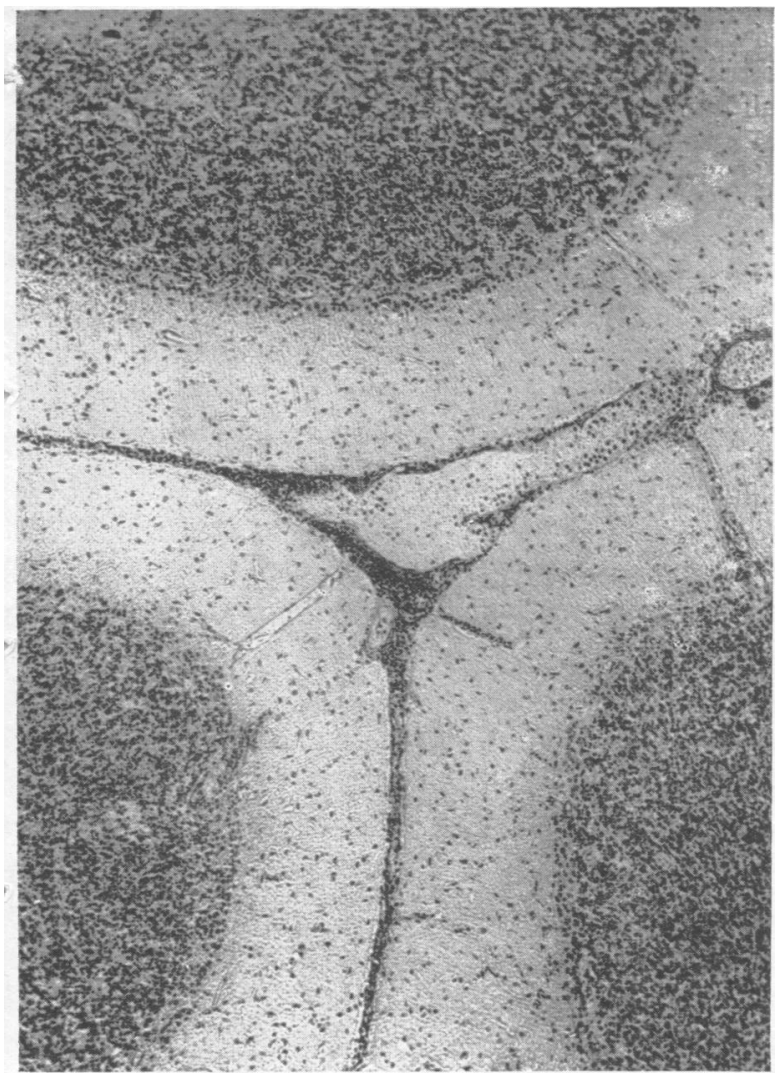

FIG. 2

Fig. 1.-Cortex of cerebellar vermis (Case 1) stained by Bielschowsky's method, showing loss of Purkinje cells with preservation of baskets and tangential fibres. The granule cells are rather sparse.

FIG. 2.-Cerebellar cortex (Case 1) stained with haematoxylin, showing widespread loss of Purkinje cells and lymphocytic infiltration of the meninges. 
staining, but in the pyramidal tracts only an occasional fibre showed the earliest sudanophil change. The degeneration of these tracts therefore appeared to increase and to be older as they passed further from their cells of origin.

No degeneration was seen either with the MarchiBusch or Scharlach $\mathbf{R}$ technique above the level of the medulla. The superior cerebellar peduncles and the strio-Luysial fibres which were degenerated in the cases of subacute-spino-cerebellar degeneration reported in 1934 by Greenfield showed no lesions in this case.

The most striking change in the cerebellum was an almost complete disappearance of Purkinje cells. This Purkinje cell loss was evenly distributed throughout the folia and convolutions, and was associated with the presence of powdery or rather more coarsely granular sudanophil lipid, chiefly extracellular, concentrated along the line of junction of the molecular and granular layers, and spreading out to a variable degree into the inner third of the molecular layer. There were also small accumulations of lipid granules in the granular layer and white matter, where they tended to be collected in microglial phagocytes. In the white centres of some folia, both in the vermis and hemispheres, as well as in the neighbourhood of the nucleus dentatus, quite large rounded fat granule cells had formed. A slight diffuse hyperplasia of microglia was present in the molecular layer. It did not anywhere take the character of glial bushwork. There was a slight loss of granule cells in some of the folia in all parts of the cerebellum, rather more widespread in the vermis than the hemispheres, but it was quite overshadowed by the wholesale loss of Purkinje cells.

In sections stained by Bielschowsky's method, the tangential fibres and baskets were well preserved, the latter being almost all quite empty, only a very few containing degenerated remains of Purkinje cells. Owing to the disappearance of the great majority of these cells very few "torpedoes" were found in the granular layer.

Celloidin sections added little to the evidences of degeneration given by frozen sections, but several points were more clearly brought out. In the spinal cord at all levels many vessels were cuffed with lymphocytes ; these were not confined to the degenerated tracts but were common in the grey horns. The infiltrations were less numerous and thinner in the lumbar than in the cervical region. Perivascular infiltrations of meningeal vessels which were scanty and sparse in the lumbar region became more severe in the cervical, and here there was also some more diffuse meningeal infiltration. In addition there were occasional glial stars, in the lateral columns, especially in relation to Clarke's column. In the medulla also fairly heavy infiltrations were seen under the floor of the ventricle and round the laterally emerging vessels. Some rather loose glial stars were seen in the nuclei of the dorsal columns. In the pons and midbrain perivascular infiltrations were quite sparse and slight and scarcely exceeded those often seen in normal brain stems. No loss of nerve cells nor gliosis was found in the inferior olives.

In the cerebellum perivascular infiltration was most evident round the meningeal vessels in the sulci, but many veins also in the white matter had a single or double cuff of lymphocytes round them. There was a general narrowing of the molecular layer with a moderate degree of isomorphous gliosis in it, associated with an increase in the number of Bergmann astrocytes. In sections stained by toluidin blue it was very difficult to find any Purkinje cells. Only an occasional shrunken cell, devoid of Nissl granules, could be found in any area. Perivascular infiltrations were abundant round the roof nuclei and present, though more sparsely, round the nucleus dentatus.

No evidence of degeneration could be found in the basal ganglia or cortex.

Summary of Case 1.-A woman' of 61 began to feel weak and ill at the beginning of April. Her gait became unsteady and her vision blurred with occasional diplopia. She also suffered from cramplike pains in the limbs which kept her awake at night. There was severe dysarthria and some aphasia and alexia. Nystagmus or lateral deviation of the eyes and slight weakness of the right side of the palate and tongue were found on examination. No sensory disturbance was found. The cerebrospinal fluid contained 48 lymphocytes and $100 \mathrm{mg}$. protein per $100 \mathrm{ml}$. and gave a strong paretic Lange curve. There was progressive physical and mental deterioration and she died on July 17, three and a half months after the onset of symptoms.

Post-mortem examination disclosed an unsuspected carcinoma of the ovary with secondaries in the pelvic and para-aortic lymph nodes, but no intracranial deposits.

Examination of the brain and spinal cord showed (1) diffuse almost complete disappearance of Purkinje cells, (2) degeneration of the direct spinocerebellar tract and more recent degeneration of the pyramidal tracts in the lower levels of the spinal cord, and (3) perivascular and meningeal infiltration with lymphocytes in the cerebellum, medulla, and spinal cord.

Case 2.-P.W.K., aged 48, a schoolmaster, was admitted to Chase Farm Hospital under Dr. George Riddoch on November 4, 1939, and died there on December 2 of that year. The history of illness, as obtained from his wife, went back to May, 1939, when he found that he was much more erratic than formerly. at lawn tennis. Otherwise he remained well till August, 1939, when he began to walk unsteadily, often bumping into his wife when he walked with her. Usually he veered to the right. He also began to drive his car badly, steering too near other vehicles as he passed them and always hitting the kerb when he pulled up. He consulted an oculist about this, and had glasses prescribed for him, but he did not himself feel that much was wrong, and was angry with his wife because she was afraid to go with him when he was driving. By September 1 he was staggering and walking like a drunken man. Owing 


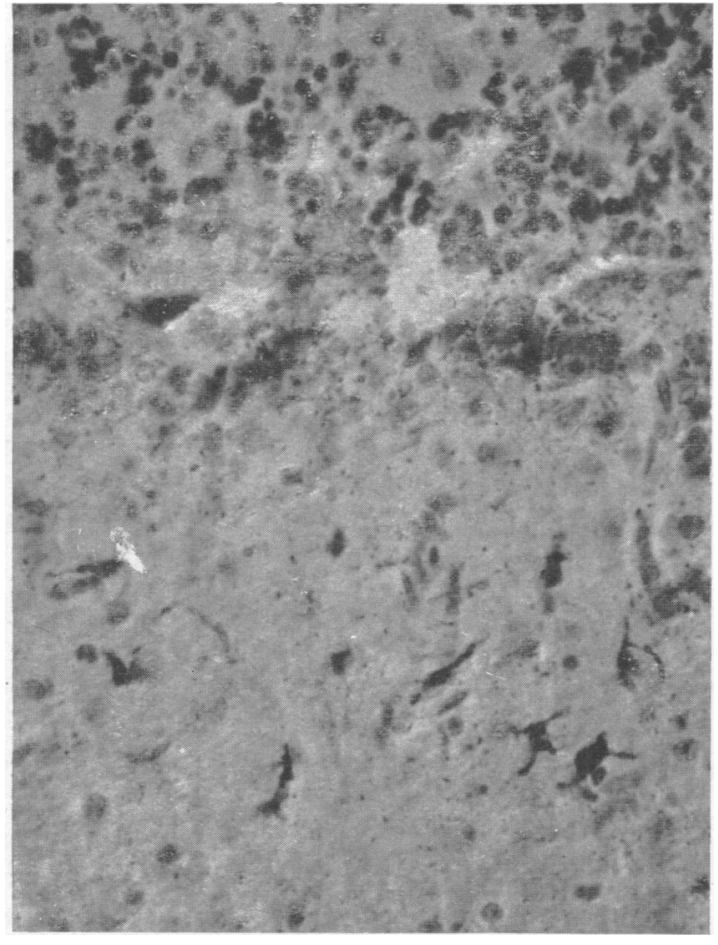

FIG. 3.-Cortex of cerebellar vermis (Case 1) stained with Scharlach R. and haematoxylin, showing microglial cells containing fat in the molecular layer. There are also fine sudanophil granules between the molecular and granular layers.

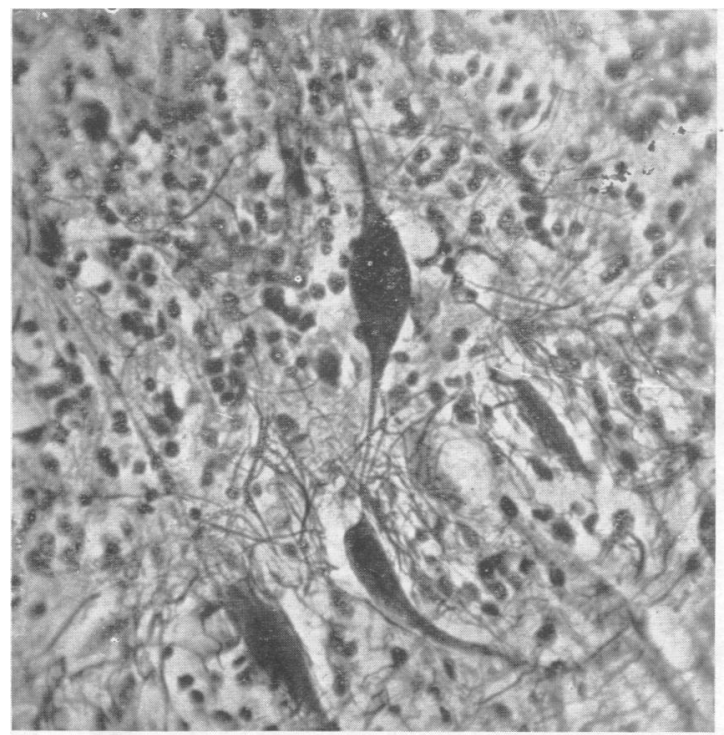

FIG. 5.-The cortex of the vermis of cerebellum (Case 2) stained by Bielschowsky's method, showing shrinkage of Purkinje cells and a "torpedo" on the axon of one of these cells.

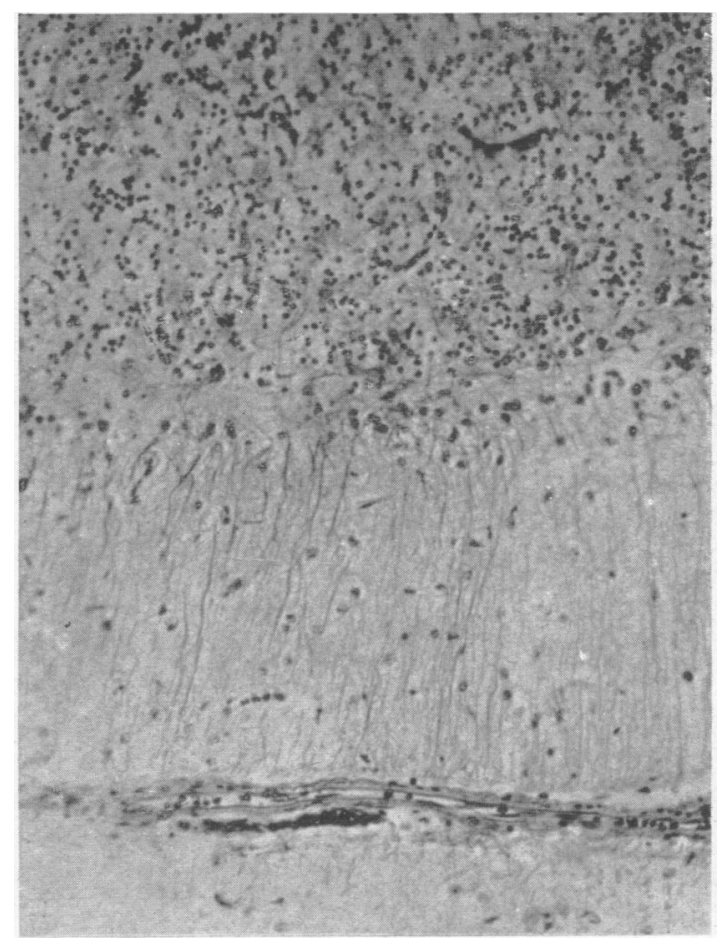

FIG. 4.-Cortex of the cerebellar vermis (Case 1) stained by Mallory's phosphotungstic acid haematoxylin showing isomorphous gliosis of the molecular layer and some sparseness of the granule cells.

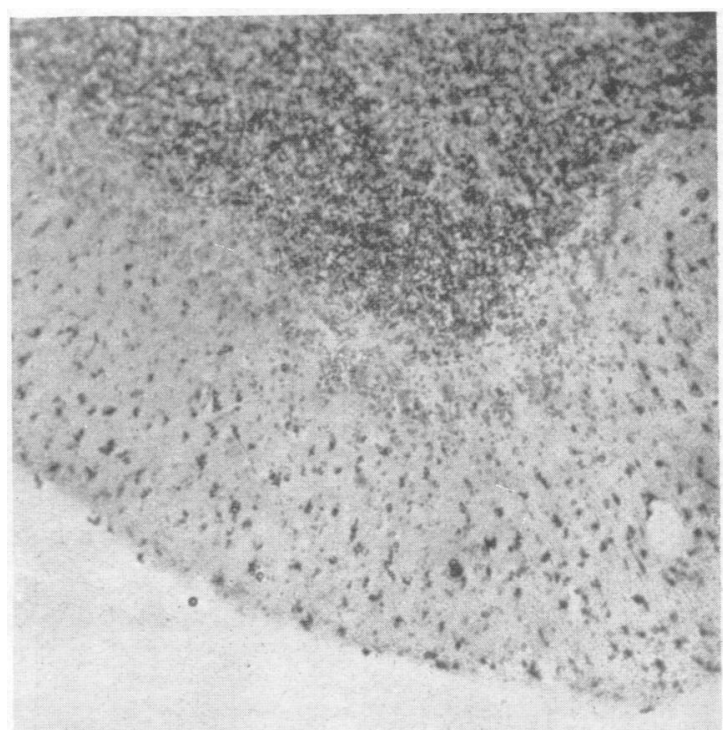

FIG. 6. - The cortex of the vermis of cerebellum (Case 2) stained by Scharlach $R$. and haematoxylin showing fatty granules collected within microglial phagocytes in the molecular layer. 
to the outbreak of war he had to evacuate his school to the country and he managed all the arrangements for this without difficulty. During the second week in September, however, he began to show evidence of mental deterioration, especially of loss of memory. His walking became progressively worse, and he fell several times, but did not hurt himself.

His arms also had become clumsy, so that he tended to knock his cup over when he put it down. For the last two weeks before he was admitted to hospital he seemed to be living in the past; he thought that he was at his old home with his parents, brothers, and sisters, and asked where his mother was, though she had been dead for eight years. He now began to realize that he was not well and that his mental faculties had deteriorated.

About the middle of September he had complained of double vision for short periods at a time, and in the last week of October this had become constant but varying in degree. The objects sometimes appeared alongside one another and occasionally one above the other, the higher being to the left. He also complained of roaring noises, like aeroplanes, and ringing noises like bells. During October his speech had become steadily more indistinct and he tended to repeat words, trying to speak them more clearly. He had had several giddy attacks in which his body seemed to rotate in a clockwise direction for about 10 minutes. They did not cause vomiting. He had learned Arabic and Hindustani during the 1914-18 war and, according to his wife, had recently talked to himself in these languages, though he had not spoken them for many years, and appeared to have forgotten them. He had become more particular as to cleanliness and neatness in his personal habits than he was before.

There had been no libido for six years. He had had venereal disease (? gonorrhoea) when in the Army in India. This had been treated by injections and there had been no recurrence. He also had had malaria in India. He had had a nervous breakdown with insomnia and loss of appetite 15 years before but had recovered after three months. He had symptoms of duodenal ulcer four years before but these had also cleared up. He smoked 20 cigarettes a day ; he drank alcohol only occasionally.

On examination it was noted that his memory was worse for recent than for past events. He was attentive and cooperative and could calculate well and had fair insight into his disability. He did not know the date, and thought that George $V$ was still alive, but had a hazy recollection of the Duke of Windsor coming to the throne. He did not know the capital of Poland nor that of the U.S.A. and could not recall what he had read recently. There was a moderate degree of dysarthria, the speech being ataxic and slightly slurred. Examination of the cranial nerves showed a slight left sided ptosis with a convergent strabismus owing to weakness of the left external rectus muscle. There was fine nystagmus on extreme deviation to the right and left, equal on the two sides, but no vertical nystagmus. The pupils were eccentric, lying slightly to the nasal side in both eyes, symmetrically. They reacted well to light and sluggishly on accommodation. The palate deviated slightly to the right on phonation.

The upper limbs were hypotonic, especially the left. The fingers of the left hand were held out of alignment and there was fine tremor in the fingers of the right hand and slight rotatory tremor of the left arm. In purposive movements there was marked ataxia with intention tremor greater in the left arm than the right, and rapid alternating movements were performed poorly, especially with the left arm. The legs also were hypotonic and ataxic, more on the left side than the right, but there was no weakness or wasting. The deep reflexes were all rather sluggish. The abdominal reflexes were present and the plantars of flexor type. No loss of cutaneous sensibility was found. His gait was grossly ataxic. He walked on a wide base with his arms hanging limply by his side and the head held rigidly. The left leg was dragged slightly. He deviated more to the left than the right when walking, and tended to fall backwards and to the left when standing with heels and toes together. His unsteadiness was not increased when he shut his eyes.

Apart from the fact that the upper part of the chest moved better on the right side than the left, there was no evidence of disease of the thoracic or abdominal organs. The blood pressure was $130 / 100 \mathrm{~mm}$. $\mathrm{Hg}$.

A lumbar puncture was performed on November 5 , 1939. The pressure was normal. The fluid contained 1 cell per c.mm. and $40 \mathrm{mg}$. protein per $100 \mathrm{ml}$. The Lange and Wassermann reactions were normal.

By November 20 the dementia had progressed considerably. The patient was drowsy and did not now speak unless spoken to, but he cooperated fairly well. There was occasional urinary incontinence.

The left pupil was larger than the right; both reacted well. There were bilateral ptosis, greater on the left side, paralysis of convergence and defective conjugate movements of the eyes to right and left, upwards and downwards. On this examination nystagmus could not be elicited. There was no change in the physical signs in the trunk or limbs, and no evidence of involvement of the pyramidal tract.

The dementia progressed rapidly and he died on December 2 about seven months after the onset of symptoms.

Necropsy Report.-A post-mortem examination limited to the brain and spinal cord was made 36 hours after death. The skull was rather thin with some roughening of the inner surface. The spinal laminae were softer than normal. The sulci of the brain were rather wide and the cerebellar folia unusually distinct, especially in the vermis. The brain weighed $1,625 \mathrm{~g}$.

After fixation in $10 \%$ formol saline solution frozen and celloidin sections were made of various areas of the cerebral cortex; sections in the mid- and parasagittal planes were made of the cerebellar vermis and hemispheres and transverse sections of the brain stem and spinal cord.

Frozen sections stained by Sudan IV and haemalum showed no evidence of degeneration except in the cerebellum where it was greatest in the vermis. Here anisotropic lipid was scattered in considerable amounts, 
mostly as intracellular accumulations in the molecular and granular layers. There was slight loss of Purkinje cells, and in sections stained by Bielschowsky's method numerous " torpedoes" were found on the axons of the Purkinje cells in the granular layer. These were more numerous in the vermis than the lateral lobes. There was also in the vermis considerable loss of baskets round the Purkinje cells; some had none, and round others the fibres were scanty. In the lateral lobes no loss of basket fibres was seen. In celloidin sections stained with toluidin blue and with iron haematoxylin, with van Gieson, and with Mallory's phosphotungstic acid haematoxylin, more severe changes were seen in the vermis than in the lateral lobes. Although there was no great loss of Purkinje cells, most of those in the vermis were shrunken and appeared as narrow elongated cells lying among greatly proliferated nuclei of Bergmann astrocytes. The cells of the granular layer also appeared more sparse than normal. In frozen sections stained by Victoria blue a diffuse isomorphous gliosis was seen in the molecular layer. In the lateral lobes the proliferation of Bergmann astrocytes and the gliosis in the molecular layer were variable ; they were slight in most places and nowhere severe. A smaller proportion of Purkinje cells was shrunken and there was no definite loss of granule cells. The nucleus dentatus appeared normal and the inferior olives showed no loss of cells ; some surcharge of lipid was present in these cells but this was probably to be explained by the patient's age and terminal illness.

Sections of the cortex, basal ganglia, brain stem and spinal cord showed no abnormality.

Summary of Case 2.-A schoolmaster, aged 48, found at the beginning of May that he was much more erratic than formerly at lawn tennis. In August he became unsteady in his gait and drove his car badly ; in September his memory became worse and he saw double, at first for short periods at a time, but later more constantly. The ataxia of his arms and legs had now become much worse.

When examined at the beginning of November there were considerable loss of memory for the events of the past few years, moderate dysarthria, strabismus due to weakness of the left external rectus muscle, slight nystagmus on lateral deviation of the eyes to either side, ataxia of the arms and legs, and a reeling gait. The cerebrospinal fluid was normal. During his stay in hospital the dementia increased rapidly to a condition of subcoma in which he died on December 2, about seven months after the first symptoms were noted.

The evidence of disease was confined to the cerebellar cortex where there was some degeneration of Purkinje cells, showing itself as shrinkage of the cell body and the formation of torpedoes on the axons. Loss of basket and tangential fibres was also evident. These changes were greatest in the vermis. No degeneration of spinal tracts or lymphocytic infiltrations were found.
Comment.-It was unfortunate that no examination was made of the thoracico-abdominal viscera in this case. Although the course of the disease did not differ greatly, if at all, from that of other cases of subacute cerebellar degeneration, the normal cerebrospinal fluid and the absence of degeneration of spinal tracts and of perivascular infiltrations distinguish the case from the other three here described which have been associated with carcinoma. It is difficult to date the onset of symptoms in this case in relation to other cases, as the loss of accuracy at lawn tennis, which was the first symptom, was a much more delicate sign of cerebellar dysfunction than the first symptoms in the other cases. Unsteadiness of gait, of sufficient degree to be noticed by his wife, did not appear for a further three months and from that time until his death about four months later the downward course of the disease was rapid. But even if we date the onset as four months before death, giving the same duration of symptoms as in Case 1, the degree of damage to the cerebellum was very much less. Whereas in Case 1 there was almost complete loss of Purkinje cells, in Case 2 the loss was slight although many cells, especially in the vermis, were shrunken and degenerated. Here, as in many cases of early disease of the central nervous system, the most definite evidence of disease was the lipid katabolism, which appeared to involve chiefly the tangential fibres of the molecular layer.

Case 3.-Mrs. B. T., aged 54, was admitted to the Radcliffe Infirmary, Oxford, on January 19, 1945, under Mr. Pennybacker. The patient had been well till the end of October, 1944, although feeling rather tired after a frontal sinusitis which she developed in mid-October. At the beginning of November her husband noticed that she seemed to be "walking on air" and holding her arms out from her sides like a tight-rope walker. The next day her arms and legs were covered with a blotchy rash which lasted three days. After this she felt very tired. She burned her leg on a hot-water bottle without being aware of it, but there had been no noteworthy loss of sensation since, and it is not clear that this accident was due to loss of skin sensibility. She became weaker, and by Christmas Day, 1944, could only walk with her husband's support.

She attended hospital as an outpatient on January 3, 1945, and saw Mr. Pennybacker. On that evening her mind appeared to wander, and continued to do so, although she had lucid intervals. She was admitted to the Radcliffe Infirmary on January 19, 1945. On being questioned there she denied having had any diplopia, visual, auditory, or olfactory hallucinations. There had been no fits, paraesthesiae, or numbness ; for the last few months there had been urgency of micturition.

On examination she was a pale, restless woman, showing considerable dysarthria. She was rational one moment and talked nonsense the next, but there 
was no nominal aphasia. Although she had difficulty in grasping objects, there was no evidence of astereognosis. She seemed to see fairly well and ophthalmoscopic examination revealed no abnormality. There was spontaneous nystagmus on convergence to the right with the slow component to the right. She was deaf in the right ear. Otherwise no evidence of involvement of the cranial nerves was found. In the upper limbs there was generalized wasting and corresponding weakness mostly in the thenar and first dorsal interosseous muscles. Tone was normal. There was some uncertainty in the finger nose test, more on the right than on the left side, and when she shut her eyes the finger missed the nose. Alternating rapid movements were performed with uncertainty. In the lower limbs there was generalized weakness but no dystonia. The legs were too weak to perform tests for coordination. The deep reflexes in the arms were normal ; the right knee jerk was absent, the left increased. The right ankle jerk was increased and the left normal. The right plantar was normal, the left doubtfully extensor. The abdominal reflexes were not obtained. There was no evident loss of superficial sensibility. Postural sensation was not impaired in the arms but the threshold was increased in the legs, and vibration sense was lost over the right ankle and diminished over the left ankle.

On January 20 lumbar puncture gave fluid with blood admixture at a pressure of $70 \mathrm{~mm}$. It contained 60 leucocytes (18 polymorphonuclears, 42 lymphocytes) and 18,000 red cells per c.mm. and $140 \mathrm{mg}$. protein per $100 \mathrm{c} . \mathrm{mm}$. (The polymorphonuclear cells and up to 10 lymphocytes were to be accounted for by the blood admixture.)

$X$-ray examination showed the shadow of the root of the right lung to be enlarged and of increased density. This appeared to arise from glandular masses in the r!ght mediastinum.

The diagnosis of carcinoma involving the mediastinal glands, right temporal lobe, and cerebellum was made. On January 29 Mr. Pennybacker found skew deviation of the eyes on looking to the left along with some difficulty in maintaining conjugate deviation. There was ataxia of the limbs which was gross on the right but less on the left side. She had difficulty in passing urine and had to be catheterized.

A blood count on this date showed :

Hb. $106 \%$, platelets 360,000 , leucocytes 6,000 per c.mm., neutrophils $56 \%$, eosinophils $1 \%$, lymphocytes $34 \%$, monocytes $8 \%$, Türck cells $1 \%$.

A second lumbar puncture on the same day gave 7 c.mm. of very slightly yellow fluid, with 9 lymphocytes and 200 red cells per c.mm.; protein $150 \mathrm{mg}$. per 100 c.mm. The Pandy reaction was strongly positive, and the Lange reaction gave a weak curve in paretic zone, 22211000 .

She was transferred to Newbury District Hospital on February 3, 1945, and died there on or about February 15 , the total duration of symptoms having thus been three and a half months.

At the post-mortem examination, which was made at the Newbury Hospital on Feburary 16, no carcinomatous deposits were found in the brain. The cerebellum and brain stem, already sliced in several places, a piece of lung showing carcinomatous invasion of the wall of a bronchus and of the surrounding alveoli, and two enlarged lymph nodes from the mediastinum were sent to Dr. Daniel. Section of the lung and lymph nodes showed an oat-celled bronchial carcinoma with secondary deposits in the lymph nodes which were largely necrotic.

Histology of the Cerebellum and Brain Stem.--Sections of the cerebellar cortex showed an almost complete loss of Purkinje, cells, with preservation of the baskets, almost all of which were empty. Here and there three or four well-preserved Purkinje cells could be seen lying close together. There was also a very noticeable loss of granule cells, the layer as a whole being narrow and its cells sparse. Some of those that remained stained well; others showed a faint, rather diffuse staining reaction and appeared to be degenerated. Moderate gliosis was seen both here and in the white matter where the most striking abnormality was cuffing of the small vessels with lymphocytes. Sections stained by Sudan IV (Scharlach R) showed early lipid degeneration in the granule cell layer and in the white matter, and numerous Marchi-stained lipid granules were present in the white matter.

There was a striking increase of Bergmann cells and fibres in the molecular layer with a microglial reaction which was both focal and diffuse. In the nucleus dentatus the cells were sparse and contained rather more lipochrome pigment than usual, and the astrocytes had rather prominent cell bodies with thick fibres passing from them. In this nucleus there were many clumps of proliferated microglial cells and some small round cells of indefinite origin. Cuffing of the vessel walls with lymphocytes was here well marked. In sections of the lower medulla slight collagenous thickening of the meninges and infiltration of these with lymphocytes was seen ; the perforating vessels, especially those of larger size, often showing well-marked lymphocytic cuffing. The cells of the inferior olive appeared to be diminished in number and contained some excess of lipochrome. Elsewhere the nerve cells appeared normal. In sections of the upper medulla the appearances were essentially similar. There was gliosis of the inferior olive, and many collections of microglial cells were seen in it; some of them appeared to be perivascular and others to be formed round the remains of nerve cells, while others appeared to have no relation either to nerve cells or vessels. The walls of some of the subependymal vessels were thickened.

Frozen sections stained by Scharlach $\mathbf{R}$ showed Sudanophil lipid in the spino-cerebellar tracts, and rather earlier myelin changes in the dorsal columns at their termination in the nuclei gracilis and cuneatus. The katabolism of myelin as shown both by Scharlach $\mathbf{R}$ and Marchi staining was greatest in the direct cerebellar tracts.

Summary of Case 3.-A woman of 54 had not felt well since the end of October when she had had frontal sinusitis. Her gait then began to be ataxic and this became worse rapidly so that by Christmas 


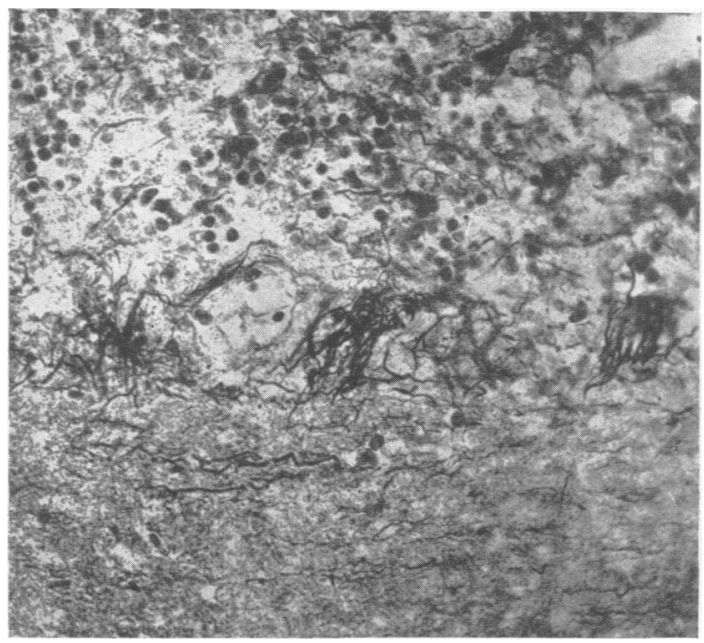

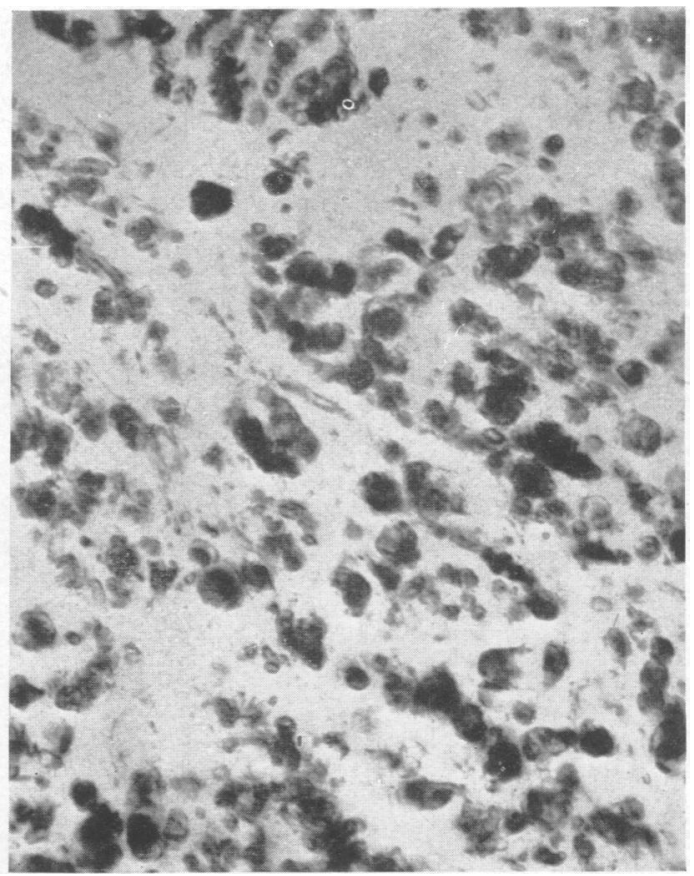

FIG. 8

FIG. 7

Fig. 7.-Cortex of the cerebellar hemisphere (Case 3) stained by Bielschowsky's. method showing empty baskets. In addition to the well-preserved fibres making up the baskets, tangential fibres are seen. Note the paucity of granule cells.

FIG. 8.-Direct spino-cerebellar tract (Case 3) in lower medulla stained Scharlach $R$ and haematoxylin showing the degenerated sudanophil myelin as black masses.

Fig. 9.--Inferior olive (Case 3) stained Mallory's phosphotungstic acid haematoxylin. Two enlarged astrocytes, one of which is binucleated, are seen on either side of a nerve cell. There is a general increased density of the neuroglial fibre network.

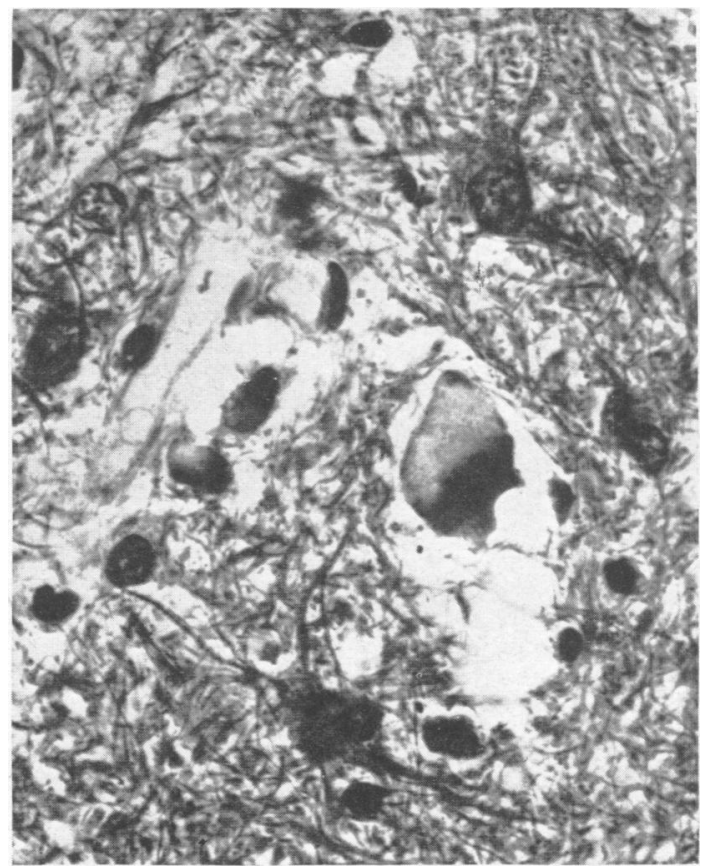

FIG. 9 
she could only walk with support. Early in January mental confusion appeared, along with dysarthria, and ataxia of the arms. There were nystagmus on right lateral deviation, some deafness in the right ear, considerable weakness and some ataxia of the arms and great weakness of the legs. The right plantar response was doubtfully extensor in type. Radiographs showed enlargement of the hilar shadow in the right side of the chest, indicating carcinoma, primary or secondary, in that region. The cerebrospinal fluid on the first examination contained an excess of cells and protein, but the examination was vitiated by blood admixture. A second examination gave 9 lymphocytes per c.mm., $150 \mathrm{mg}$. protein per $100 \mathrm{ml}$., and a weak Lange curve in the paretic zone, 22211000. Skew deviation of the eyes on looking to the left and some failure to maintain conjugate deviation were present at this time. The patient died in the middle of February three and a half months after the onset of symptoms.

Post-mortem examination showed a bronchial carcinoma with involvement of the hilar lymph nodes.

The changes in the nervous system were similar to those in Case 1, namely, (1) practically complete loss of Purkinje cells with preservation of baskets ; (2) degeneration of the direct spino-cerebellar tracts, and a less severe and more recent degeneration of the dorsal columns; (3) lymphocytic infiltrations and glial stars in the cerebellum and medulla.

Case 4.-A.C., a man aged 56, was admitted to the Radcliffe Infirmary, Oxford, under Mr. Pennybacker, on November 9, 1945, and died there on November 19. His history was that on demobilization from the army in June 1945, he had been medically examined and found perfectly fit. At this time he felt quite well, but one week later he, along with several of the men in his unit, had a sharp attack of diarrhoea and vomiting. On July 7, he went for a week's holiday to Blackpool and while there had aching pains in his knees and shins, such as he had had with malaria. This pain passed off in two days. On his return to work in the middle of July, he had severe indigestion with aching pains in the umbilical region and on the right side of the abdomen, coming on immediately after a meal. He was off work with this for three weeks, and at the end of that time was quite free from pain and felt well. On his return to work, however, he found that he was quite tired out by a full day's work, and he became progressively unsteady on his feet, until he was afraid of being dismissed for being drunk on duty. At that time he had pains in the lumbar region, calves and knees radiating up the thighs and down to the feet. These pains were exacerbated by exercise. He was also giddy in the sense that he felt as if he were drunk. Subsequently he had vertigo, especially if he turned his head suddenly. He gave up work, because of these symptoms, after seven weeks.

Early in October he noticed that his vision was blurred and he had periods of diplopia, the images being sometimes one above the other and sometimes side by side. On admission he could only read with a magnifying glass, with one eye closed. He had been in bed since the end of October.

His family history contained nothing of interest. His wife and three daughters aged 18, 8, and 5 years were well. His parents had died at advanced ages. One brother was well and another had died from wounds in the 1914-18 war. He had smoked fewer than 10 cigarettes a day and drank less than a pint of beer a week.

On examination he was an intelligent man, able to give a full history, and to cooperate well. He looked strong and well. The glands in the groins were palpable but not hard or tender.

Examination of the cranial nerves showed his vision when corrected to be $6 / 12 \mathrm{R}$ and $6 / 9 \mathrm{~L}$ with full fields. There was bilateral papilloedema. Nystagmus was present in all positions of the eyes, slow and coarse to the left, rapid and fine to the right. The right pupil was larger than the left and reacted more briskly to light; both pupils contracted on accommodation-convergence. No other abnormalities of cranial nerve function were found. The upper limbs were hypotonic, but strong. Slight intention tremor was present in both arms in the finger-nose test, but no dysdiadokokinesis, or clumsiness on rapid alternating movements. In the lower limbs tone and power were normal, but there was slight incoordination in the right leg in the heel to knee test. The deep reflexes in the arms were rather weak on the left side, the right knee jerk was stronger than the left and the right ankle jerk weaker than the left. The abdominal reflexes were absent and the plantars doubtfully flexor in type. His gait was grossly ataxic with a wide base. He was unable to stand with his eyes open for more than a few seconds. Sensibility was normal over the body and limbs to all forms of stimulus. There was a large, left-sided hydrocele; examination of the thoracico-abdominal viscera showed no abnormality. His blood pressure was $135 / 90$. It had been found to be $200 / 100$ before his admission to the Radcliffe Infirmary. The pain in his back and legs had now almost disappeared. Lumbar puncture on November 12 gave faintly blood-stained fluid at a pressure of $260 \mathrm{~mm}$. It contained 22 lymphocytes per c.mm. and $80 \mathrm{mg}$. protein per $100 \mathrm{ml}$. The Lange reaction was not performed.

As the symptoms and physical signs indicated a cerebellar neoplasm, subtentorial decompression was performed by Mr. Pennybacker on November 13, but the only abnormality found was thickening of the arachnoid which in places was adherent to the dura mater. The patient recovered well from the operation, but during the night of November 14 became restless, and by the next morning he had become cyanosed and semi-comatose with stertorous breathing. The wound was re-opened and a large haemorrhage was found passing into the cerebellum. This was removed as far as possible, and the patient's condition improved for 
a time, but this improvement was not maintained and he died on November 19, four and a half months after the onset of symptoms.

A post-mortem examination was performed on the following day. The bronchi contained much mucopus. The upper and lower lobes of the right lung contained focal areas of pneumonic consolidation which were breaking down in some places. Elsewhere the lungs were congested. There were dense adhesions of the left lung to the diaphragm. The hilar lymph nodes were large, purple and fleshy. On section of the lungs after fixation, firm, greyish tissue was seen adjacent to the smaller bronchi in a number of places in the right upper lobe, but no ulceration of bronchi or clear evidence of tumour was found. The heart weighed $400 \mathrm{~g}$., but was otherwise normal ; its vessels were in good condition. The suprarenal gland on either side contained a rounded soft homogeneous grey mass of tumour. This measured $2 \mathrm{~cm}$. on the right side and was rather smaller on the left. No other tumour masses were found in the abdominal cavity. The prostate was soft with a few small areas resembling simple hyperplasia. There was a large hydrocele, with a cyst in the head of the epididymis, on the left side. The left testis appeared normal, the right atrophic and soft with a smaller hydrocele.

On histological examination the firm areas in the right lung consisted of infiltrations by an oat-celled carcinoma of bronchial type. The growths in the suprarenal and the infiltrations in the bronchial lymph nodes were of similar character.

Examination of the Central Nervous System.-The posterior parts of both cerebellar hemispheres were rather fragmented and haemorrhagic from operative trauma and the cisterna magna was filled with blood clot, as was also the ventricular system. Section of the brain after fixation showed slight ventricular dilatation, but no evidence of secondary deposits of tumour. In the cerebellum there was a recent operative cavity in the superior vermis and left cerebellar lobe, the adjacent tissue being studded with petechial haemorrhages. The spinal cord was, unfortunately, not examined, but as the brain was removed by approach from the back, several of the upper cervical segments were taken out along with the brain stem.

Histological Examination.-The meninges over the cerebellum were slightly thicker than normal and were infiltrated by lymphocytes, plasma cells, and some macrophages. Numerous red blood cells were also present. In the molecular layer of the cerebellum there was a slight diffuse increase of microglial nuclei, as well as many foci resembling glial "bush-work"; some of these lay round vessels. The Purkinje cells were lost over considerable stretches where the Bergmann astrocytes were proliferated, but the loss was much less than in Cases 1 and 3. The tangential fibres and basket fibres were preserved and there were many empty baskets. In most of the remaining Purkinje cells the Nissl granules were powdery, but in a few they were quite normal. The nuclei of the granular layer were decreased in number but those that remained appeared

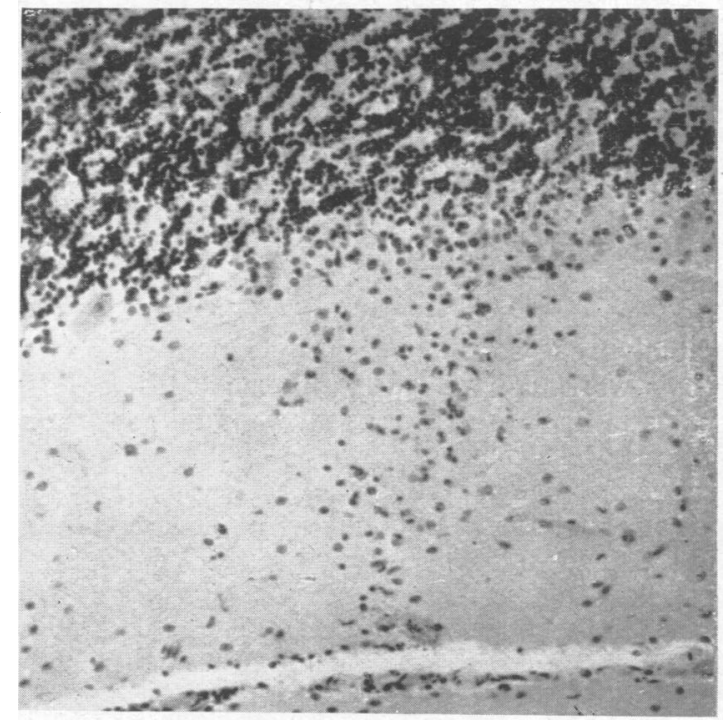

FIG. 10. Cerebellar cortex (Case 4) stained by haematoxylin showing microglial "bush" appearance (gliastrauchwerk) along the dendrites of a Purkinje cell which has degenerated. $\times 150$.

normal. No "torpedoes" could be found in this layer. No loss of nerve cells was found in the nucleus dentatus, though there was a slight increase in lipochrome pigment in its neurons. The astrocytes here showed slight enlargement of the cell body and thickening of their fibres, and slight perivascular infiltration was also seen in this area.

In the medulla similar changes were seen in and around the inferior olives and in the restiform body, and some glial stars were also present in these areas. Sections stained by Scharlach $\mathbf{R}$ and haemalum showed in the cerebellum some granular stippling and small collections of lipid granules along the line of the Purkinje cells, and more sparsely among the granules. Very little sudanophil lipid was found in the centres of the folia, but the Marchi-Busch technique revealed some early degeneration here.

In the cervical cord fairly heavy infiltration of the meninges with lymphocytes and macrophages was present and the perforating vessels were cuffed with similar cells. A few glial stars were present in the grey matter. The direct spino-cerebellar tracts showed degeneration both with the Marchi-Busch technique and with Scharlach $\mathbf{R}$, and early changes in the myelin of the dorsal columns were seen by the latter method.

No definite changes either with cell stains or with the Marchi-Busch technique were found in the pons or midbrain. In the putamen and caudate several of the medium sized veins were thrombosed and there was some lymphocytic infiltration of their walls as well as in those of veins under the walls of the ventricles. A few glial stars were also seen here. In the supraoptic nucleus there was a definite excess of microglial 
nuclei, and some perivascular lymphocytic cuffing. Many of the nerve cells of this nucleus contained crystals of formol-haemoglobin pigment. A small focus of softening was present in the white matter of the occipital lobe and there was slight perivascular and meningeal infiltration in this region.

Summary of Case 4.-A previously healthy man of 56 began in July, 1945, to have aching pains in the legs for two days, and thereafter became rapidly weak so that he was very tired after a full day's work and walked like a drunken man. The pains in his legs returned and were made worse by exercise. He felt giddy when he turned his head suddenly. He had to give up work in October and at this time suffered from diplopia. On examination in hospital on November 9 there was bilateral papilloedema and nystagmus in all positions of the eyes. The upper limbs were hypotonic and slight intention tremor was present but no other evidence of cerebellar incoordination. In the lower limbs also incoordination was slight, but the gait was grossly ataxic with a wide base, and he was unable to stand steadily. The cerebrospinal fluid contained 22 lymphocytes per c.mm. and $80 \mathrm{mg}$. per $100 \mathrm{ml}$. of protein. The Lange reaction was not performed. The Wassermann reaction was negative. A subtentorial decompression operation was performed on November 13. This was followed by a reactionary haemorrhage into the cerebellum and the patient died six days later.

Necropsy.-The right lung, mediastinal lymph nodes and both suprarenals were invaded by an oat-celled bronchial carcinoma. No secondary growths were found in the brain or elsewhere in the body. On examination of the nervous system the most evident lesions were (1) loss of many Purkinje cells with preservation of baskets, and slight rarefaction of granule cells; (2) early degeneration of the direct cerebellar tracts and dorsal columns; and (3) lymphocytic cuffing in the cerebellum, medulla, and spinal cord.

\section{Discussion}

In these four cases symptoms of cerebellar disease developed fairly rapidly in subjects past middle age and contributed to their death at intervals of three and a half to seven months from the onset of the disease. Post-mortem examination showed diffuse degeneration of the cerebellar cortex and in three also degeneration of one or more of the long tracts of the spinal cord. In these three cases there was also carcinoma; of the lung in two and of the ovary in one. In two of the three cases carcinoma was unsuspected during life.
The relationship of this small subacute group to the larger group of cortical cerebellar degenerations has been recently discussed by Zülch (1948). He divides cortical cerebellar atrophies into five groups : (1) chronic cortical (grey) atrophy, affecting the vermis especially, which is an exaggeration of local ageing, without evident exogenous influence ; (2) a group of cases with an acute course and apparently an extrinsic causation, especially neoplasm, many dying of the cancer rather than of cerebellar disease ; (3) a group having an acute or sub-chronic course, coming on with acute general disease, e.g. enteritis, syphilis, tuberculosis or alcoholism, in which the cerebellar degeneration may cease to progress when the cause ceases to act, but may regress in later life ; (4) a group in which cerebellar disease has been present from childhood but is progressive ; (5) familial cases.

Zülch's second and third groups interest us here especially. While it is not clear what he means by the terms " acute" and "subchronic" he suggests that such forms of cerebellar disease are not rare. Yet we have been unable to find more than 12 cases in the literature in which the disease has run its course in less than a year, including the two recorded by Greenfield in 1934 and the four here recorded. The others were reported by Murri (1910), Schroeder and Kirschbaum (1928), Casper (1929), Zülch (1936), Alessi (1940), and MunchPetersen (1947). In considering this subacute group it is convenient to add cases with a rather longer history, up to about two years, as they have many features in common with those which prove fatal under a year from the onset. Such cases were recorded by Parker and Kernohan (1933) 27 months, Kennard (1935), 18 months, Zülch (1936), 19 months, and Brouwer and Schlesinger (1947), $14 \frac{1}{2}$ months. Thus 16 subacute cases in all will be considered in this discussion. The subacute cases reported by Akelaitis (1938) have not been included here as they belong to the familial group of cerebelloolivary degeneration, but in them, as in three of our present cases and five of the previously recorded cases, there were also symptoms of mental disease.

Clinical.-This subacute group is characterized clinically by the rapid appearance of cerebellar symptoms. \& Unsteadiness of gait is usually the first or a very early symptom and is followed later by clumsiness of the hands and đैysarthric speech. After a few weeks or months the incoordination becomes so severe that the patient is no longer able to sit up unsupported. A less usual early symptom of cerebellar disease is diplopia, which was present in all the four cases here recorded.' In three it was a fairly early symptom and had been present before 
admission to hospital, while in Case 3 it was only noted, along with skew deviation of the eyes, on examination in hospital. This symptom is well recognized as an early sign of cerebellar tumour, and attention has been drawn by two of us to its occurrence during the earlier phases of subacute cerebellar disease of demyelinating character in young children (Brain and Greenfield, 1950). Its occurrence in cortical cerebellar degeneration is not so unusual as textbook descriptions of the disease would suggest. It was an early symptom in the cases reported by Casper and Kennard and in one of those reported by Zülch. In most of these cases the diplopia varied from time to time and appears to have been due to lack of balance rather than to paralysis of eye muscles.

$\triangle$ Nystagmus appears to be more common in subacute than in chronic cases of cortical cerebellar degeneration. In their classical paper on this condition Parker and Kernohan say that there are rarely more than a few unsustained jerks of the eyes on lateral deviation. However, definite nystagmus was present in the four cases recorded hore, as well as in six of the other twelve cases under review.

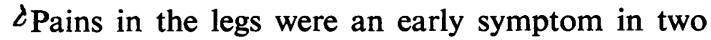
patients of the present series as well as in one of those recorded in 1934. In Case 1 these were described as cramp-like and were severe enough to keep the patient awake at night. In Case 4 they were the first symptom, resembling at their onset the pains of malaria. Although at first transient, the pain returned as radiating pains in the lumbar region, thighs, and legs down to the feet. In Greenfield's Case 2 (1934), the iirst symptom was shooting pains in the legs, severe eilough to cause sweating. It was tempting to relate this symptom to the degeneration of the dorsal roots, which was present in Greenfield's Case 2, but no degeneration of these was found in Case 1 of the present series. This symptom, however, as well as the degeneration of the dorsal columns when it occurs, links these cases with those of polyneuritis associated with carcinoma described by Denny-Brown (1948) and by Lennox and Prichard (1950).

$\approx$ Mental deterioration was also a fairly early symptom in three of these cases, as also in Greenfield's (1934) cases. In Case 2 it took the form of loss of memory for recent events with relative preservation of memory for those long past. In this respect the subacute cases of cortical cerebellar atrophy differ from the more chronic cases in which the mind usually remains clear.

The cerebrospinal fluid showed excess of cells and protein in the three cases associated with carcinoma. In one of these a strong Lange reaction of paretic type was also present. Similar fluids with excess of cells and protein were recorded by Greenfield (1934) and Munch-Petersen (1947), and fluids with abnormal Lange reactions but no excess of cells by Parker and Kernohan (1933), Kennard (1935), and Brouwer and Schlesinger (1947).

Pathology.-The most striking fact that appears in surveying these subacute cases of cortical cerebellar degeneration is that 11 of the 16 have had carcinoma. Not all have died of this, and it is often impossible from the details given to estimate to what extent carcinoma was responsible for death. In two of the three cases of bronchial carcinoma (Greenfield, 1934, and Case 3 of the present series) death was certainly hastened by carcinoma, but in Case 4 the immediate cause of death was cerebellar haemorrhage following a subtentorial craniotomy. In five cases there was carcinoma of the ovary (Parker and Kernohan, 1933 ; Kennard, 1935 ; Zülch, 1936; Brouwer and Schlesinger, 1947; and Case 1 of the present series). In two cases, Zülch (1936) and Alessi (1940), there was uterine cancer. Casper's case had a recurrence of mammary carcinoma, and in Greenfield's Case 1 (1934) a tumour of the breast had been removed within a year of death, but as the post-mortem examination was limited to the brain and spinal cord it was not known whether the tumour had recurred.

The relationship of carcinoma to the disease of the nervous system is not very clear. That it has some such relationship is evident from the much higher incidence of carcinoma in these cases with a subacute course (11 or 12 out of 16 cases) than in those with a more gradual onset and slower course. Thus Parker and Kernohan only cite one case of carcinoma of the pancreas (Lhermitte, 1922), among 10 cases of chronic parenchymatous cortical cerebellar atrophy. The curious case, with a rapid onset and then a prolonged standstill of symptoms, reported by Bertrand and Godet-Guillain (1942a) appears to be the only case associated with carcinoma among the many cases of chronic cortical cerebellar atrophy reported since Parker and Kernohan's paper and does not therefore affect their figures. Considering the average dura-

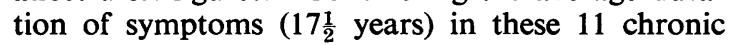
cases and the fact that seven of them reached their sixtieth year, the incidence of carcinoma cannot be shown to be greater in them than in the general population. It is also remarkable that in the 11 subacute cases with definite carcinoma, the primary site of tumour has been most often in the lung and ovary.

Cerebellar Degeneration.-In subacute cortical cerebellar degeneration there is usually a wide- 
spread degeneration and disappearance of Purkinje cells, with a lesser degree of degeneration of the neurons of the granular layer and little or no damage to the basket cells and tangential fibres. This degeneration is diffuse affecting the vermis at least as much as the hemispheres. In two of the four cases here reported the degeneration of Purkinje cells was almost complete; very few remained and these were severely degenerated. In the two other cases the degeneration was earlier and much less universal. In Case 2 it was most evident in the vermis where there was considerable evidence of myelin katabolism; a larger number of torpedoes were also present on the axons of the Purkinje cells. In addition to slight loss of Purkinje cells and granule cells there was in this case considerable loss of basket cells and fibres. This is unusual in cortical cerebellar atrophy, especially in subacute cases in which this system is usually relatively if not completely spared. In Case 4 the loss of Purkinje cells was greater, and was associated with the microglial " bush-work" which is often seen in the more acute focal degenerations of Purkinje cells, but is unusual in diffuse cerebellar degenerations. Here also some loss of granule cells was seen but the basket cells appeared to be intact.

The nucleus dentatus showed only minor changes in these four cases and there was no evidence of degeneration in the superior cerebellar peduncle. This system has, however, shown a varying degree of degeneration in four of the 16 cases under review (Greenfield's Case 2, 1934; Kennard, 1935; Brouwer and Schlesinger, 1947 ; Munch-Petersen, 1948).

Degeneration of the long tracts of the spinal cord was present in the three cases of the present series associated with carcinoma, as also in Casper's (1929) case, Greenfield's (1934) cases, and one of Zülch's (1936) cases. In several others either no examination was made of the spinal cord or it was only stained by the Weigert-Pal technique, which might well have failed to demonstrate early degeneration. In our cases degeneration was most common and usually most advanced in the direct spino-cerebellar tract. Next in frequency came degeneration of the dorsal columns. Degeneration of dorsal roots was not found except in Greenfield's Case 1 (1934). The pyramidal degeneration was rarely evident at the level of the medulla and was most severe in the lumbar segments of the cord. In the dorsal columns also the degeneration appeared to be oldest in the parts of the nerve fibres which are furthest from the corresponding nerve cells in the dorsal root ganglia, but Zülch draws attention to the special incidence of the degeneration on Flechsig's middle root zone, which is primarily affected also in tabes dorsalis.
'The presence of spinal degeneration in at least seven of the 16 cases of subacute cortical cerebellar degneration under review make it more than a casual accompaniment, and justify the name "subacute spino-cerebellar degeneration" used by Greenfield (1934). At the same time, the complete integrity of the spinal cord in Case 2 of the present series, and the absence of degeneration in one or another of the long tracts in other cases where methods to demonstrate recent degeneration have been employed, indicate that spinal degeneration is not constant. It may be more common in the cases associated with carcinoma, but the number of cases adequately examined is too small for any certain knowledge on this point. This assumption, however, would bring the spinal degeneration into line with the peripheral neuropathies found in association with carcinoma (Denny-Brown, 1948), an association which Lennox and Prichard (1950) have shown to be more than a chance one.

The meningeal and perivascular lymphocytic infiltrations which were found in the three cases of this series associated with carcinoma deserve a brief mention. Such infiltration was found also in the neighbourhood of degenerated systems in the two cases described by Greenfield (1934), but, apart from these five cases, has only been found in one other, that of Brouwiwer and Schlesinger (1947). In spite of the pleocytosis in the cerebrospinal fluid in his case, Munch-Petersen (1947) found no such infiltration. We consider it a reaction to rapidly degenerating nervous tissue ("symptomatic" in Spielmeyer's sense) rather than as having any aetiological significance.

In this series of cases the inferior olives were normal or almost so, the gliosis and slight loss of neurons in Case 3 (Fig. 9) being the only definite change. The inferior olives were also stated to be normal in 11 of the 12 other cases in the group under review ; the only exception was the case of Schroeder and Kirschbaum (1928) in which considerable damage to this nucleus was seen, many neurons being lost and others reduced to shadows. In this respect the group of cortical cerebellar degeneration differs from that of hereditary cerebello-olivary degeneration. It seems probable that the olivary degeneration in these cases is secondary to degeneration in the cerebellar cortex as first suggested by Holmes (1907) seeing that it is limited to the parts of the olive which correspond to the most degenerate areas of cerebellar cortex (e.g., dorsal laminae of the olives when the superior cerebellar convolutions are most degenerated); but if so it is not clear why it should be more often present in familial than in non-familial cases of the same chronicity. It is probable, though not certain, that 
the olivo-cerebellar fibres terminate as mossy fibres among the neurons of the granular layer. If so, trans-synaptic degeneration of the olivary neurons should follow degeneration of the granule cells, and is not so likely to occur when the Purkinje cells are more selectively damaged. On the other hand the subacute familial cases of cerebello-olivary degeneration reported by Akelaitis (1938) suggest that the combination of olivary with cerebellar cortical degeneration may be inherent in the hereditary gene.

Aetiology and Pathogenesis.-In seeking for an explanation of the rapid degeneration of Purkinje cells in the group of cases under review, we must take into account the special vulnerability of these cells which has been shown both in human disease and in experimental studies. There are, in fact, many extrinsic poisons and abnormal metabolic states to which the Purkinje cells are particularly vulnerable. These include ischaemia, e.g., from temporary arrest of the circulation (Kabat, Dennis, and Baker, 1941), heat stroke (Freeman and Dutnoff, 1944 ; Krainer, 1949), the toxins of typhus fever and scarlatina (Spielmeyer 1922), and various poisons including lead (de Villaverde, 1927). The effect of alcohol on cerebellar functions is well known, and chronic intoxication has been blamed

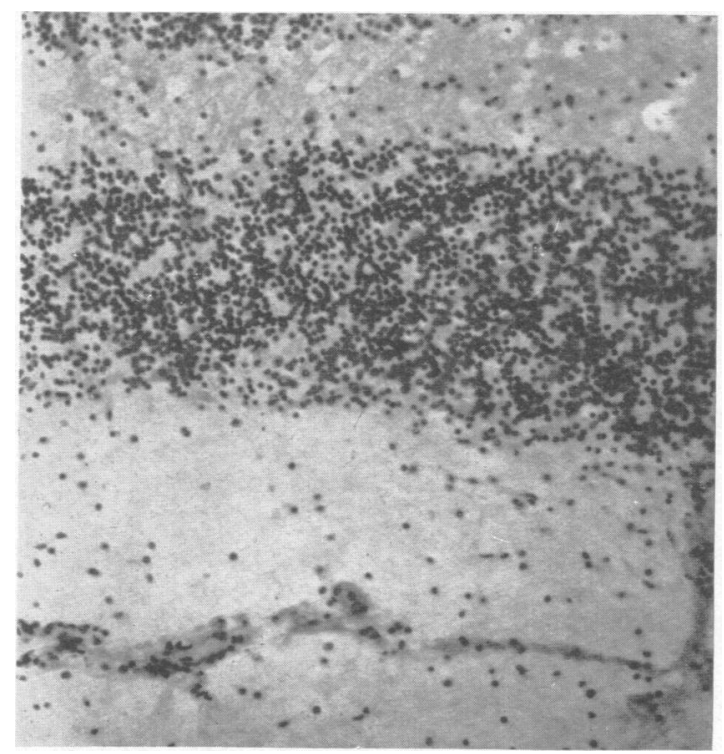

FIG. 11.-Cerebellar cortex of a rabbit which had received an intracerebral injection of material from the lymph node of a patient with lymphadenoma. Note the complete disappearance of Purkinje cells without other change. $\times 150$. (By the courtesy of Dr. Ruby O. Stern).

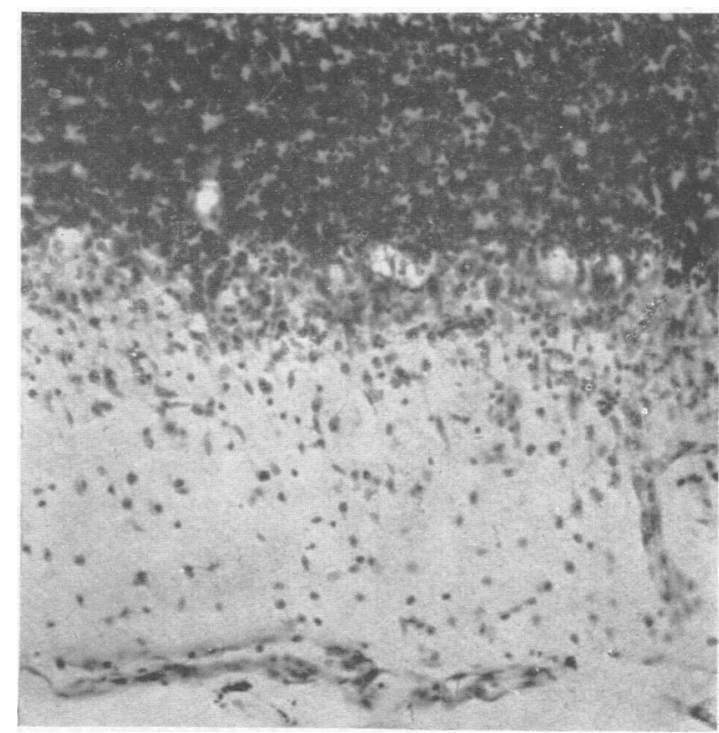

FIG 12.-Cerebellar cortex of a guinea-pig which had received an intracerebral injection of primate bone marrow. There is in this area disappearance of Purkinje cells associated with a mobilization of the microglia. $\times 150$ (Nissl stain). (By the courtesy of Dr. Lester King.)

as the cause of cerebellar degeneration in several cases, but in many of these the symptoms have continued to progress in spite of total abstinence from alcoholic drink, and in other respects the relationship as to cause and effect is by no means clear. Zülch (1948) has collected 27 cases of cortical cerebellar degeneration which he could attribute to a toxic cause. These cases ran an "acute or subchronic" course. The suspected cause was neoplasm in eight, alcohol in five, enteritis in four, syphilis in four, tuberculosis in two, and other toxic factors in four.

The association of cancer with rapid degeneration of Purkinje cells recalls the experimental work of Gordon (1932) on lymphadenoma, and the subsequent experiments of Friedemann and Elkeles (1933) and of Kelser and King (1936), who showed that intra-cerebral injections of primate bone marrow produced in rabbits and guinea-pigs wholesale destruction of Purkinje cells. This effect was later traced by Edward (1938) and by Turner, Jackson, and Parker (1938) to the action of eosinophil leucocytes. It is well known that a high eosinophilia may appear in the blood in cases of carcinoma, especially of the ovary, but there is no record of such an association in any of the reported cases of subacute cerebellar degeneration, nor is it known whether, or to what extent, there was carcinomatous invasion of the bone marrow in these cases. 
Parker and Kernohan (1933) suggested that chronic infection by a virus might play some part in the aetiology of the disease. While there is more evidence at the present time than in 1933 that subacute or even chronic disease of the nervous system may be caused by viruses, the systematized nature of the disease does not favour such an aetiology. Although in some cases perivascular and meningeal infiltrations have been present, we regard these, as has been said, as secondary to the rapid degeneration of neurons, and as having the same significance as the mobilization of microglia into " bush-work" in the cerebellar cortex. The special attack of the virus of "louping-ill " on the Purkinje cells in the sheep and monkey instanced by Parker and Kernohan does not appear to occur in man, as no symptoms suggesting cerebellar disease have been seen in human cases of infection by this virus, nor does the closely related virus of Russian tickborne encephalitis tend to affect the cerebellum selectively.

Bertrand and Godet-Guillain (1942b) found a peculiar degeneration of the granule cells in 16 of 16 cases dying of carcinoma. They describe the granule cell layer as having an iced ("glacé ") naked-eye appearance, and its nuclei, microscopically, as staining poorly by Nissi's method, many having indefinite contours. The Purkinje cells in these cases appeared normal. An examination of 21 cases dying of carcinoma at the National Hospital, London, during recent years has not confirmed these findings. In only one was this change in the granule cells seen; it was of moderate degree and was confined to the deeper lamellae, the more superficial, both on the upper and lower surfaces, being intact. The patient died early in August and the postmortem examination was not made till the following day, when autolytic changes were present in the organs of the body cavity ; for example, the nuclei of the convoluted tubules of the kidney completely failed to stain. It is true that the majority of these patients died from spread of the carcinoma to the brain or spinal cord, rather than from its effects on the metabolism of the body. We agree with Bertrand and Godet-Guillain that this change in the granule cells is frequently seen in patients dying in diabetic coma. The change in the granular layer does not appear to have any clinical counterpart, and the early and partial character of the nuclear degeneration, added to the fact that it is sometimes confined to areas of cortex which lie at some depth from the surface, suggest that the condition is partly agonal and partly due to post-mortem autolysis, that is, changes in the cells beginning shortly before death may render them especially liable to autolytic changes.
The granule cell layer is generally much less vulnerable than the layer of Purkinje cells, the only other known cause of selective degeneration of the layer being poisoning with methyl mercury salts (Hunter, Bomford, and Russell, 1940).

The nucleus dentatus is also prone to be affected by severe toxic states such as typhus fever (Spielmeyer, 1921) and may show degenerative changes due to the fatal illness (Scherer, 1932). It is therefore wise to discount the part played by degenerative changes in this nucleus in causing symptoms unless well established myelin degeneration is found in the superior peduncle.

Conclusion.-It is clear that we are not dealing here with a sharply defined pathological syndrome or disease entity but with rare cases in which degeneration of Purkinje cells comes on rapidly, sometimes associated with degeneration of related systems and tracts, especially the spino-cerebellar tract and the superior cerebellar peduncle. In the majority of these subacute cases carcinoma appears to play an aetiological part, either by some special alteration of the bodily metabolism or in combination with some other factor at present unknown. There is no evidence that heredity plays any part in the aetiology, but the processes of local ageing, called by Gowers "abiotrophy," and the special vulnerability of the Purkinje cells and nucleus dentatus probably determine the site of attack. That the equally vulnerable cells of the cerebral cortex may also be affected is shown by the association of dementia in many of the cases, but technical difficulties, especially the large area of cortex to be examined, make a histological assessment of the degree of degeneration in it difficult and uncertain.

\section{Summary}

Four cases of subacute cortical cerebellar degeneration are described. In three of these there was also degeneration of the long tracts of the spinal cord (direct spino-cerebellar in all, pyramidal in one, and dorsal columns in the other two).

In these three cases there was also carcinoma, of the bronchi in two and of the ovary in one.

Progressive dementia appeared soon after the onset of cerebellar symptoms in three of the four cases. Diplopia of the cerebellar type was present in all and was an early symptom in three. Cramplike pains in the legs heralded the onset of cerebellar symptoms in two cases.

A review of the literature shows a high correlation of carcinoma with subacute cortical cerebellar degeneration. Of cases which have run their course in two years, more than two-thirds have had carcinoma, although this has not always been 
clinically evident. The more chronic forms of cerebellar degeneration show no such correlation.

In considering the pathogenesis of the disease, emphasis is laid on the special vulnerability of the Purkinje cells to extrinsic poisons or intrinsic metabolic disturbances, but no explanation is found in this for the rarity of the disease.

It is a pleasure to acknowledge our gratitude to Mr. Pennybacker for permission to record Cases 3 and 4 and to the medical staff of Newbury Hospital for their cooperation.

\section{REFERENCES}

Alessi, D. (1940). Riv. Pat. nerv. ment., 55, 148.

Akelaitis, A. J. (1938). Amer. J. Psychiat., 94, 1115. Bertrand, I., and Godet-Guillain, J. (1942a). Rev. neurol, 74, 287.

neul, (1942b). C.R. Soc. Biol., Paris, 136, 664.

Brain, W. R., and Greenfield, J. G. (1950). Brain, 73. In the press.

Brouwer, B., and Biemond, A. (1938). J. belge Neurol. Psychiat., 38, 691. and Schlesinger, F. G. (1947). Proc. K. nederl. Akad. Wet., 50, 1329.

Casper, J. (1929). Zbl. ges. Neurol. Psychiat., 53, 854.

Denny-Brown, D. (1948). Journal of Neurology, Neurosurgery and Psychiatry, 11, 73.

Edward, D. G. ff. (1938). Lancet, 1, 936.

Freeman, W., and Dutnoff, E. (1944). Arch. Neurol. Psychiat., Chicago, 51, 67.

Friedemann, U., and Elkeles, A. (1933). Brit. med. J., 2, 1110.
Gordon, M. H. (1932). In " Rose research on Lymphadenoma," by Horder, T. H., Gordon, M. H., Stone, K., Garrod, L. P., Culliman, E. R., and Pullinger, B. D.; p. 7. Bristol and London.

Greenfield, J. G. (1934). Brain, 57, 161.

Holmes, G. (1907). Ibid., 30, 466.

Hunter, D., Bomford, R. R., and Russell, D. S. (1940). Quart. J. Med., 9, 193.

Kabat, H., Dennis, C., and Baker, A. B. (1941). Amer. J. Physiol., 132, 737.

Kelser, R. A., and King, L. S. (1936). Amer. J. Path., 12, 317.

Kennard, M. A. (1935). Proc. K. Akad. Wet., 38, 544.

Krainer, L. (1949). Arch. Neurol. Psychiat., Chicago, 61, 441 .

Lennox, B., and Prichard, S. (1950). Quart. J. Med., $43,97$.

Lhermitte, J. (1922). Rev. neurol., 29, 313.

Munch-Petersen, C. J. (1947). Acta psychiat., Kbh., Suppl. 46, p. 213.

Murri, A. (1910). Riv. crit. Clin. Med., 1, 593, 609.

Parker, H. L., and Kernohan, J. W. (1933). Brain, 56, 191.

Scherer, H. J. (1932). Z. ges. Neurol. Psychiat., 139, 337.

Schroeder, A. H., and Kirschbaum, W. (1928). Ibid., 114, 681.

Spielmeyer, W. (1922). " Histopathologie des Nervensystems." Berlin.

Thomas, A. (1939). C.R. 3 Congrès. Neurologique International, Copenhague, 1939, p. 189.

Turner, J. C., Jackson, H., and Parker, F. (1938). Amer. J. med. Sci., 195, 27.

Villaverde, J. M. de (1927). Trab. Lab. Invest. biol. Univ. Madr., 25, 41.

Zülch, K. J. (1936). Z. ges. Neurol. Psychiat., 156, 493. _- (1948). Dtsch. Z. Nervenheilk., 159, 501. 